\title{
Chronic Atrial Fibrillation
}

National Cancer Institute

\section{Source}

National Cancer Institute. Chronic Atrial Fibrillation. NCI Thesaurus. Code C80392.

A disorder characterized by a long standing and persistent uncoordinated atrial

myocardium activation due to multiple reentry circuits with consequent deterioration of atrial mechanical function. Instead of intermittently contracting, the atria quiver continuously in a chaotic pattern, causing a totally irregular, often tachycardia ventricular rate. On the ECG it is characterized by the replacement of consistent $P$ waves by rapid oscillations or fibrillatory waves that vary in size, shape, and timing, associated with an irregular, frequently rapid ventricular response when atrioventricular conduction is intact. 